Georgia State University

ScholarWorks @ Georgia State University

\title{
Grandparents as Family Caregivers: Lessons for Intergenerational Education
}

Nancy P. Kropf

Georgia State University, nkropf@gsu.edu

Denise Burnett

Follow this and additional works at: https://scholarworks.gsu.edu/ssw_facpub

Part of the Social Work Commons

\section{Recommended Citation}

Kropf, Nancy P. and Burnett, Denise, "Grandparents as Family Caregivers: Lessons for Intergenerational Education" (2003). SW Publications. 9.

https://scholarworks.gsu.edu/ssw_facpub/9

This Article is brought to you for free and open access by the School of Social Work at ScholarWorks @ Georgia State University. It has been accepted for inclusion in SW Publications by an authorized administrator of ScholarWorks @ Georgia State University. For more information, please contact scholarworks@gsu.edu. 


\title{
Grandparents as Family Caregivers: \\ Lessons for Intergenerational Education
}

\author{
Nancy P. Kropf, PhD \\ School of Social Work \\ University of Georgia \\ and \\ Denise Burnette, PhD \\ School of Social Work \\ Columbia University
}

PUBLISHED IN: Educational Gerontology, 29, 361-372.

RUNNING HEAD: Grandparents as Family Caregivers

NOTE: This paper was presented as the Closing Plenary, Association for Gerontology in Higher Education, Twenty-eighth Annual Meeting and Educational Leadership Conference, March 3, 2002. 


\title{
Grandparents as Family Caregivers:
}

\section{Lessons for Intergenerational Education}

\begin{abstract}
The number of grandparents who have responsibility for raising grandchildren has increased dramatically over the past several decades. From an educational perspective, content on custodial grandparents can promote an increased interest in, and understanding of, the complexities of aging by stressing the intergenerational aspects of this family form. This paper describes the growing population of custodial grandparents, and the larger socioenvironmental contexts of these families. In addition, it highlights instructional approaches for including content on grandparent-headed families within didactic and experiential courses.
\end{abstract}




\section{Grandparents as Family Caregivers: \\ Lessons for Intergenerational Education}

Within the older population, older adults assume a wide variety of social and familial roles. In terms of family caregiving, the older adult is usually presumed to be the care recipient, and the care provider, a spouse or adult child. While many families do provide assistance to older adults, others are aided by older family members who care for younger generations. For examples, many older adults have long continued to function as parental caregivers for adult children who have development, psychiatric, or physical disabilities.

Custodial grandparenting has emerged as another critical family caregiving role for older adults. These grandparents assume primary, and at times sole, responsibility for raising their grandchildren. In about one-third of these households, there are no parents present. Data from the 2000 Census indicate that an estimated 8.4 percent of American children live in households headed by non-parental relatives. About three quarters of these children are cared for by grandparents - meaning that between 2.3 million and 2.4 million grandparents are primary caregivers for 6.3 percent, or 4.5 million, children (see Bryson, 2001). Clearly, the experience of providing surrogate parent care for grandchildren is a role that is assumed by a significant and steadily growing number of middle-aged and older adults.

\section{Who are Grandparent Caregivers?}

Historically, grandparents have fulfilled multiple familial roles, including supportive and supplemental childcare. However, the reasons that underlie increased custodial grandparenting are more complex and pose novel challenges for grandparent caregivers. The major precipitating 
factor for this family configuration is parent substance abuse, which is implicated in the majority of cases. The crack cocaine epidemic of the 1980s had an especially strong, still visible, impact on the increased number of grandparent caregivers and on the challenges these caregivers face (Burton, 1992; Minkler, Roe, \& Price, 1992; Minkler, Roe, \& Robertson-Beckley, 1994; Roe, Minkler, \& Barnwell, 1994; Roe, Minkler, Saunders, \& Thomson, 1996). Concomitant, often interrelated contributing social problems include child maltreatment, HIV/ AIDS infection, and maternal incarceration (Barnhill, 1996; Dressel \& Barnhill, 1994; Grant, Gordon, \& Cohen, 1997; Joslin, 2002). With respect to HIV/AIDS, grandparents may be raising children orphaned and/or infected by the disease, and in some cases, their ill parents as well (Caliandro \& Hughes, 1998; Poindexter \& Linsk, 1999; Whetten-Goldstein \& Nguyen, 2001).

Research on custodial grandparenting has identified several stressful aspects of this role. Raising children is physically demanding, and the role demands may contribute to development and or exacerbation of existing health and functional problems (Bowers \& Myers, 1999; Jendrek, 1993; Minkler \& Fuller-Thomson, 1999; Morrow-Kondos et al., 1997; Musil, 1998; Poindexter \& Linsk, 1999; Szinovacz, DeViney, \& Atkinson, 1999). Grandparent caregivers are also at increased risk of depressive symptomatology (Minkler, Fuller-Thomson, Miller, \& Driver, 1997), and their social relationships often suffer, as demands of caregiving diminish opportunities for meaningful, sustained contact with established social networks (Burnette, 1999; Jendrek, 1993; Minkler, Roe, \& Robertson-Beckley, 1994; Strawbridge et al., 1997).

On the other hand, grandparents who are raising their grandchildren consistently report that the experience adds joy and meaning to their lives and provides them with companionship and a purposeful social and familial role. In addition, their caregiving role serves an important kin-keeping function for their family and the larger society (Morrow-Kondos, Weber, Cooper, \& 
Hesser, 1997; Poindexter \& Linsk, 1999).

The custodial role often leads grandparents to contacts with a wide range of loosely connected and poorly coordinated formal service providers. Child welfare staff may interact with grandparent caregivers in terms of kinship care and permanency planning (Kolomer, 2000), and school systems are often encountered. School based personnel, such as social workers, teachers, and nurses, may interact with grandparents around children’s behavior, learning, and health problems or when relocation issues arise when a child moves into a grandparent's home. Legal professionals are also commonly involved with custodial grandparents for matters such as custody, estate planning, or adoption procedures. In addition, health care providers address the health-related needs of both grandparents and the children in their care.

The involvement of multiple professions in the individual and family care of grandparentheaded families across the life course, along with the rapid growth of this family configuration, makes it highly likely that students will encounter these families in their practice. Teaching content on grandparents as family caregivers provides instructors with the opportunity to frame professional issues within an intergenerational context. The remaining sections of this paper provide an overview of various content areas related to grandparents as family caregivers that could be effectively integrated in undergraduate and graduate curricula across disciplines.

\section{Teaching Content on Grandparents as Family Caregivers}

Custodial grandparenting raises a wide range of practice and policy issues, which in turn provide a rich array of opportunities for teaching students about aging. A discussion of various strategies for teaching this topic will illustrate how content can be integrated in curricula across disciplines, and a discussion of teaching outcomes on this topic will provide a rationale for including content on intergenerational families to enhance students= understanding of aging 
within families and communities.

\section{Rationale for Curricular Content on Grandparent Caregiving}

Excite students for aging. Despite the "demographic imperative” of our aging society, students in most practicing professions eschew gerontology and geriatrics in favor of other population groups. Aging has remained a woefully low career choice in social work since the 1970s (Brody, 1970; Kropf, Schneider, \& Stahlman, 1993), for example, and the same holds for other health and social service professions. As a result, most professionals are ill-prepared to meet the challenges of working with an increasingly older client base (Peterson \& Wendt, 1990).

Teaching content on grandparents who are raising their grandchildren may well stimulate students’ interest in aging. One strategy might be to examine the Aoff-time@ quality of this parenting role and its impact at the individual, family and community level. Content might focus on the role transition and role ambiguity that stem from a grandparent's parenting of a grandchild and the effects of this transition on the individual and family. Students may be asked to examine new instrumental and developmental tasks custodial grandparents must assume in this role, e.g., becoming a disciplinarian or relinquishing long-held expectations of leisure time in later life. The impact of grandparent caregiving on other family roles and relationships, e.g., with a spouse or non-custodial grandchildren, might also be fruitfully explored.

Generational issues in parenting can also be used to highlight the experience of contemporary custodial grandparents vis-à-vis important sociohistorical features of family life. Exploration of changes in reasons for grandparent caregiving and the norms of parenting since grandparents raised their own children can highlight the dynamic context of family roles. An example shared by one older grandmother illustrates the challenges that grandparents must often negotiate. Despite their living marginally above the poverty threshold and struggling to purchase 
family necessities, her grandson was outraged when she would not buy expensive athletic shoes for him like those his peers wore. She could not understand the value her grandson placed on these shoes, and she struggled to help him understand this decision. The example highlights the impact of social change on intergenerational relations and it raises important issues of family communication.

Diversity of family forms. A popular news magazine recently featured a cover story on whether there is a typical contemporary family form (Kantrowitz \& Wingert, 2001). The twoparent, multiple-child family that typified mid-century America is now complemented by many other forms and structures. The "traditional family" of today includes families headed by grandparents, same-sex couples, single and step parents.

There are also significant sources of diversity within grandparent-headed families, which are disproportionately families of color, yet are well represented across racial and ethnic groups and income strata. Another important source of variation is type of community. About onequarter of grandparent-headed families live in rural areas, and they differ from their urban counterparts in terms of access to health and social services and feelings of disempowerment within their communities (Myers, Kropf \& Robinson, 2002; Robinson, Kropf, \& Myers, 2000).

Value and productivity of older adults. Custodial grandparents are making a major contribution to their families, their communities, and society. One early popular press article described grandparents as the >silent saviours= of the next generation (Creighton, 1991). These grandparents, who are predominantly women, serve as a safety net between their grandchildren and the formal foster care system. Course content that emphasizes these positive contributions to family and society will also help correct flawed images of older adults as uniformly frail and dependent. 
As noted, grandparent caregiving can be fraught with stress, strain, and burden given the significant challenges it poses across multiple domains of functioning and well being. Yet, the experience typically also engenders positive outcomes, including the satisfaction of nurturing and sustaining family ties and enjoying the companionship of a grandchild and meaningful ties with younger generations (Pruchno, 1999). Contrary to the common conceptualization of late life as a time of role loss, childrearing can provide some grandparents with a valued and valuable family and social role. This experience of custodial grandparents also supports theoretical formulations of family caregiving more generally as characterized by both strain and gain (Pearlin, Mullen, Semple, \& Skaff, 1990).

Social policy. Grandparent-headed families also provide a rich instance for analyzing social and family policy. Students often have difficulty grasping the connection between public policies that emanate from macro social and economic forces and the micro-level conditions of individual and family lives. Families headed by grandparents afford them an opportunity to examine policies across the domains of child welfare, aging, housing, health care, and income maintenance. And, since numerous policy arenas impact these families, they provide a rare occasion for analysis of gaps in policy that place these families at risk of "falling through the cracks.”

Grandparent-headed families also illustrate the importance of examining policies across federal, state and local jurisdictions. The legal status of grandparent-grandchild relationship (e.g., informal care, custody, guardianship, adoption, or kinship foster care), for example, may depend on the locality in which they live and their relationship largely determines whether and to what extent the family is entitled to various resources and the power to make autonomous decisions. Finally, students also struggle with the value assumptions inherent in social policy. To 
extend the abovementioned example, the values that underpin the grandparents' eligibility for various sources of public support have been hotly debated. Specifically, assuming that most grandparent caregivers will share role-related needs, should their eligibility for services vary by the legal status of their relationship with their grandchild? Discussions of this debate could focus on the point at which a family is treated as a legal unit, with attendant rights and responsibilities.

\section{Teaching Strategies}

There are numerous ways to present content on grandparents who are raising grandchildren that can enrich the scope and depth of aging issues in the curriculum. The methods selected depend in part on the teaching and learning objectives of a course and also on the need to tailor the desired knowledge and skills to the discipline-specific context. The following sections present three sample strategies: case studies, videos and service learning projects.

Case studies. Case studies can be used to enhance students' understanding of the salient dimensions of an older adult's experiences in raising a grandchild. Narrative accounts of the experience can serve to highlight role relationships and adaptations of various family members,

e.g., the marital dyad, grandparent-non-custodial grandchild, and/or the grandparent-parent-child relationship if a parent remains involved. Such accounts could also reveal important information on the internal family dynamics and the family's relationship and functioning in its particular social world. Linkages to other important social institutions in the community might also be stressed, such as grandparents' relationship to the school setting and how a grandchild perceives this connection. Case studies are also an ideal approach for examining longitudinal issues, such as changes in family structure and family dynamics over time. For example, how does a family adapt when a parent is released from prison or a grandparent becomes ill? The following case, which involves a grandparent who is raising her two grandsons, is illustrative. Several suggested 
discussion points are offered after the narrative.

Mrs. Smith, age 62, is caring for her two grandsons Mike, aged 9 and Jack, aged 13. The children's mother was killed by their father in a domestic dispute and he is now serving a life sentence in another state. Mrs. Smith rents a modest home in a rural community and receives disability payments for severe arthritis. Her husband died about 15 years ago in a railway accident.

Mrs. Smith is a kinship foster parent for Mike but not for Jack. She has few other family members to whom she can turn to for support. She states that she needs help urgently, as Jack has recently become involved in the juvenile justice system for throwing rocks at school buses. She is worried that he will be taken away from the home, and is concerned about his temper and increasing aggressive episodes.

Mrs. Smith loves both of her grandsons, and feels particularly sad for Jack who witnessed the murder of his mother. Although she has limited income, she purchased a motorcycle for Jack, perhaps to help compensate for the loss of his mother and in hopes of making him happy. She states that she does not understand why he dresses in shabby, baggy clothes and listens to loud music. She also states that she feels self conscious in her small community.

This case provides several possible discussion points. First is the experience of profound grief and loss in the family, particularly of Mrs. Smith's daughter and the children's mother. Other major losses include the traditional Agrandparenting@ role for Mrs. Smith, the experience of relocation for both boys, and possibly the loss of economic security with the need to raise two adolescent boys. Grief and loss are often present in grandparent-headed families.

Students can also discuss existing and needed connections of the Smith family to various 
agencies within the community. Mrs. Smith must become familiar with a number of new social institutions, such as the schools, the juvenile justice system, and possibly health, mental health and public welfare. In addition to her new caregiver role, she is also entering new Aclient@ roles. This experience appears to be compounded by her living in a small, rural community where she feels anxious about public exposure and possible stigma surrounding her life circumstances.

Finally, students might be asked to identify the social policies that assist and perhaps constrain the various resources this family needs. Such an exercise could focus on needs of individual family members and of the family as a whole.

Videos. Several videos that are readily available can be used highlight the strengths and needs of grandparent-headed families. One titled "That's a Family" (Chasnoff \& Cohen, 2000) portrays these families as one of many diverse family forms, including blended, single parent, same sex, and adoptive families. This video enables students to examine the strong points and the challenges of different family forms using a comparative framework.

Other videos can be used to address specific issues of custodial grandparenting. Two excellent examples, “Divided Loyalties” (Ortiz, 1994) and “Big Mama” (Seretean, 2000), profile families in which grandparents are raising grandchildren. This type of video encourages students to consider the family as a case study, focusing first on precipitating factors and pathways into care such as drugs, violence, and parental death, and then moving to the unfolding story of the stresses, challenges, and rewards that grandparents experience in their childrearing role.

Service learning. Another approach to teaching about this intergenerational family form is through service learning projects. Service learning is a type of community service designed to promote student education and development, along with promoting community goals (Gray, Ondaatje \& Zakaras, 1999). Service learning is used across disciplines and has grown rapidly as 
an instructional method. In 1985, the concept of service learning was endorsed by a handful of college presidents to promote community service for students and provide national leadership in bringing universities together with their communities. Since that time, the number of students involved in service learning has grown 3663\% (National Service Learning Clearinghouse, 1999).

Service learning has tremendous potential in fields where students are reluctant to engage in particular social issues or with marginalized populations. In gerontology, service learning experiences provide an opportunity for students to become more familiar with older adults, and to demythologize unfounded stereotypes about their experiences. In an analysis of service learning in a long term care facility, for example, fully 90 percent of students reported that the experience was useful in their education. In addition, significant positive changes were found in their attitudes toward older adults from pre- to post- experience (Hegeman, 1999).

Service learning projects can easily be structured for work with grandparents who are raising grandchildren. Some projects could focus on the grandchildren and their experience in living with their grandparents. These children may feel isolated or stigmatized, and may perceive of their family as different, and perhaps inferior, to families of other children. In a program to support grandparents who are raising grandchildren in a rural area, for example, a children=s group was formed to provide social outlets and mutual aid. On the first outing, the grandchildren were transported on a field trip. One girl saw another grandmother walking her grandchild to the van and exclaimed, “Oh, she lives with her grandmother too!” (Robinson \& Kropf, 2002). This event was normalizing and provided a sense of shared experience for the children involved.

Other projects may focus on grandparents as the unit of service, or on the family system. Service learning projects could have the goal of helping custodial grandparents to navigate the complicated array of service options and link them with needed community resources. For 
example, students could compile a list of relevant local, state, and national organizations for distribution to custodial grandparents. This type of resource could be distributed through schools or local churches, which are most likely to have contact with these families. Other projects may promote a sense of inclusion for grandparents in community organizations. "Grandparents as Parents Day” might be held at a school or a council on aging to bring together other grandparentheaded families for a program or fellowship. The goal of this type of project could be to heighten public awareness of grandparents who are raising their grandchildren and to enhance their sense of belonging in the community.

In summary, content on grandparents who are raising grandchildren may be easily integrated into a range of professional curricula. Such content could encourage students who are not otherwise attracted to gerontology to engage in aging issues through their interest in and work with children, families, and communities and realize that aging is an integral feature of family life. This content also has the potential to heighten students' awareness of the resilience and productivity of older adults. Too often, family care is conceptualized solely as care for older adults. Examples of families in which grandparents are raising grandchildren expand the concept and understanding of family care, and erode the myth that older adults have little to contribute to family systems. Finally, this family configuration offers a promising venue for demonstrating the intricate connections between family life, well being and social policy issues. Depending on the course and discipline, there are a number of highly flexible methods for including content on integenerational families within the curricula of higher education. 


\section{References}

Grandparents as Family Caregivers

Barnhill, S. (1996). Three generations at risk: Imprisoned women, their children, and grandmother caregivers. Generations, Spring, 39-4

Bowers, B.F., \& Myers, B.J. (1999). Grandmothers providing care for grandchildren: Consequences of various levels of caregiving. Family Relations, 47, 385-393.

Brody, E. (1970). Serving the aged: Education needs viewed by practice. Social Work, $\underline{15}, 42-51$

Burnette, D. (1996). Physical and emotional well-being of custodial grandparents in Latino families. American Journal of Orthopsychiatry, 69 (3), 305-318.

Burton, L.M., (1992). Black grandparents rearing children of drug-addicted parents: Stressors, outcomes, and social service needs. The Gerontologist, 36(2), 199-208.

Caliandro, G., \& Hughes, C. (1998). The experience of being a grandmother who is the primary caregiver for her HIV-positive grandchild. Nursing Research, $\underline{47}(2)$. 107-113.

Chasnoff, D. (Director) \& Cohen, H. S. (Executive Producer) (2000). That’s a family! [Videotape]. (Available from Women’s Educational Media, 2180 Bryant Street, Suite \#203, San Francisco, CA 94110).

Creighton, R. (1991). “Silent saviours”: Grandparents raising grandchildren. Newsweek.

Dressel, P.L., \& Branhill, S.K. (1994). Reframing gerontological thought and practice: The case of grandmothers with daughters in prison. The Gerontologist, 34(5), 1994.

Grant, R., Gordon, S.G., \& Cohen, S.T. (1997). An innovative school-based intergenerational model to serve grandparent caregivers. Journal of Gerontological Social Work, 28(1/2), 47-60. 


\section{Grandparents as Family Caregivers}

Gray, M.J., Ondaatje, E.H., \& Zakaras, L. (1999). Combining service and learning in higher education. Santa Monica, CA: RAND Corporation.

Hegeman, C.R. (1999, Novemeber). Service learning in elder care. Paper presented at the Gerontological Association of America, San Fransisco, CA.

Jendrek, M.P. (1993). Grandparents who parent their grandchildren: Effects on lifestyle. Journal of Marriage and the Family, 55, 609-621.

Joslin, D. (Ed.) (2002). Invisible caregivers: Older adults raising children in the wake of

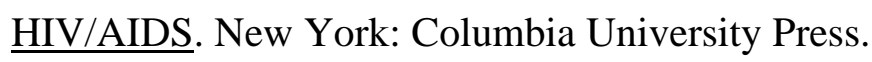

Kantrowitz, B. \& Wingert, P. (2001, May 28). Unmarried, with children. Newsweek, 46 $-54$.

Kolomer, S. (2000). Kinship foster care and its impact on grandmother caregivers. Journal of Gerontological Social Work, 33, 85-102.

Kropf, N. P., Schneider, R. L. \& Stahlman, S. D. (1993). The status of baccalaureate social work education. Educational Gerontology, 19, 623-634.

Lugalia, T. (1998). Marital status and living arrangements: March 1998. Washington, DC: Bureau of the Census.

Minkler, M. \& Fuller-Thomson, E. (1999). The health of grandparents raising grandchildren: Results of a national study. American Journal of Public Health, $\underline{\text { 89 }}, 1-6$.

Minkler, M., Fuller-Thomson, E., Miller, E., \& Driver, D. (1997). Depression in grandparents raising grandchildren. Archives of Family Medicine, $\underline{6}$, 445-452.

Minkler, M., Roe, K.M., \& Price, M. (1992). The physical and emotional health of grandmothers raising grandchildren in the crack cocaine epidemic. The Gerontologist, 32(6), 752-761. 
Minkler, M., Roe, K.M., \& Robertson-Beckley, R.J. (1994). Raising grandchildren from crack-cocaine households: Effects on family and friendship ties of AfricanAmerican women. American Journal of Orthopsychiatry, 64(1), 20-29.

Morrow-Kondos, D., Weber, J.A., Cooper, K., \& Hesser, J.L. (1997). Becoming parents Again: Grandparents raising grandchildren. Journal of Gerontological Social Work, 28

Myers. L. L, Kropf, N. P \& Robinson, M. M. (2002). Grandparents raising grandchildren: Case management in a rural setting. Journal of Human Behavior in the Social Environment, $\underline{5}(1), 53-71$.

Musil, C.M. (1998). Health, stress, coping, and social support in grandmother caregivers.

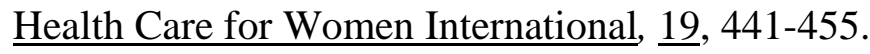

Ortiz, R. (Producer) (1994). Divided loyalties: Grandparents raising grandchildren. [Videotape]. (Available from Aquarius Health Care Videos , Olde Medfield Square , 266 Main Street, Suite 33B, Medfield, MA 02052).

Pearlin, L.I., Mullen, J.T., Semple, S.J., Skaff, M.M. (1990). Caregiving and the stress process: An overview of concepts and their measures. The Gerontologist, $\underline{30}$ (5), 583-594.

Peterson, D. A. \& Wendt, P. F. (1990). Employment in the field of aging: A survey of professionals in four fields. The Gerontologist, $\underline{30}$, 679-684.

Poindexter, C.P., \& Linsk, N.L. (1999). “I’m just glad that I’m here”: Stories of seven African American HIV-affected grandmothers. Journal of Gerontological

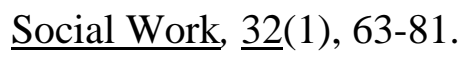

Pruchno, R. (1999). Raising grandchildren: The experience of Black \& White grandmothers. The Gerontologist, 39(209-221). 
Robinson, M.M., Kropf, N.P., \& Myers, L. (2000). Grandparents raising grandchildren in rural communities. Journal of Aging and Mental Health, $\underline{6}(4), 1-13$.

Roe, K.M., Minkler, M., \& Barnwell, R.S. (1994). The assumption of caregiving: Grandmothers raising the children of the crack cocaine epidemic. Qualitative Health Research, 4(3), 281-303.

Roe, K.M., Minkler, M., Saunders, F.F., \& Thomson, G.E. (1996). Health of grand mothers raising children of the crack cocaine epidemic. Medical Care, 34(11), 1072-1084.

Seretean, T. (Producer/Director) (2000). Big Mama. [Videotape]. (Available from California Newsreel, P.O. Box 2284, South Burlington, VT 05407).

Strawbridge, W.M., Wallhagen, J.I., Shema, S.J., \& Kaplan, G.A. (1997). New burdens or more of the same? Comparing grandparent, spouse, and adult-child caregivers. The Gerontologist, 37(4), 505-510.

Szinovacs, M.E., DeViney, S., \& Atkinson, M.P. (1999). Effects of surrogate parenting on grandparents’ well-being. Journal of Gerontology: Social Sciences, $\underline{54 \mathrm{~B}}(6)$, S376-S388.

Whetton-Goldstein, K., \& Nguyen, T.Q. (2001). Characteristics of individuals Infected with the human immunodeficiency virus and the provider interaction in the predominantly rural southeast. Southern Medical Journal, 94(2), 212222. 